\title{
VARIA
}

\section{MISCELÁNEA DE PINTURA DECIMONÓNICA}

El objeto de estas líneas es el de dar a conocer una serie de obras de diversos pintores del siglo xIx, que nos han ido llegando a lo largo de cierto tiempo y por diferentes conductos, y que, por no prestarse a ser publicadas individualmente, queremos hacerlo ahora en conjunto, ya que hemos reunido las suficientes para conformar un pequeño trabajo que pensamos tendrá, aunque sea al menos, el valor de aportar su existencia y conocimiento.

Presentándolas por orden cronológico de sus autores, la primera de ellas, procedente de colección particular, es un hermoso dibujo acuarelado de $0,18 \times 0,24 \mathrm{~m}$. del pintor romántico español Jenaro Pérez Villaamil, y que por su asunto podríamos titular Contrabando de tabaco con el norte de África (Fig. 1). Se halla firmada en el ángulo inferior derecho «G. P. de Villaamil», con inconfundible caligrafía del artista; y, en el lateral derecho de la obra, sobre el primero de los dos fardos que están representados encima de dicha firma, hay escrito con letras mayúsculas la palabra «TABACOS» y debajo de esta la inscripción, para nosotros sin sentido, de «FAL».

Se trata, como decimos, de un dibujo de una finura de rasgos y de una estilización de los personajes que recuerda a obras semejantes de J. F. Lewis. Esta elegancia de trazos se complementa con los delicados toques de colorido a la aguada, repartidos aquí y allá estratégicamente en la superficie de la obra, en los que se combinan acertada y equilibradamente las tonalidades frías de beiges y verdes que dominan en el fondo de la composición, con las más cálidas de rojos y amarillos que resaltan en las vestimentas de los personajes.

En cuanto a su temática, podemos decir que en ella se aúnan dos asuntos de tratamiento típicamente romántico: la figura del contrabandista, tan caro al costumbrismo romántico, tanto nacional como extranjero; y el orientalismo, género de lo más característico en la iconografía romántica. Ambas temáticas fueron ampliamente tratadas por Jenaro Pérez Villaamil ${ }^{2}$, quien fue prácticamente pionero, junto con Escacena y Daza ${ }^{2}$, en la introducción de los asuntos orientalistas en la pintura romántica española.

De Juan Pérez Villaamil, hermano de Jenaro, traemos un cuadro, firmado y fechado, hacia el ángulo inferior derecho, «J. Villaamil (palabra ilegible) 1838», que fue ofrecido hace unos años al Museo de Pontevedra para su posible compra por un particular que como de Jenaro lo creía, y que no fue finalmente adquirido por dicho museo. Desconocemos sus dimensiones,

\footnotetext{
1 Arias Anglés, E., «Pérez Villaamil y los inicios del orientalismo en la pintura española», Archivo Español de Arte, 281, 1998, p. 1.

2 Arias Anglés, E., «Escacena y Daza, pionero del orientalismo romántico español», Archivo Español de Arte, núm. 287, 1999 , p. 279.
} 

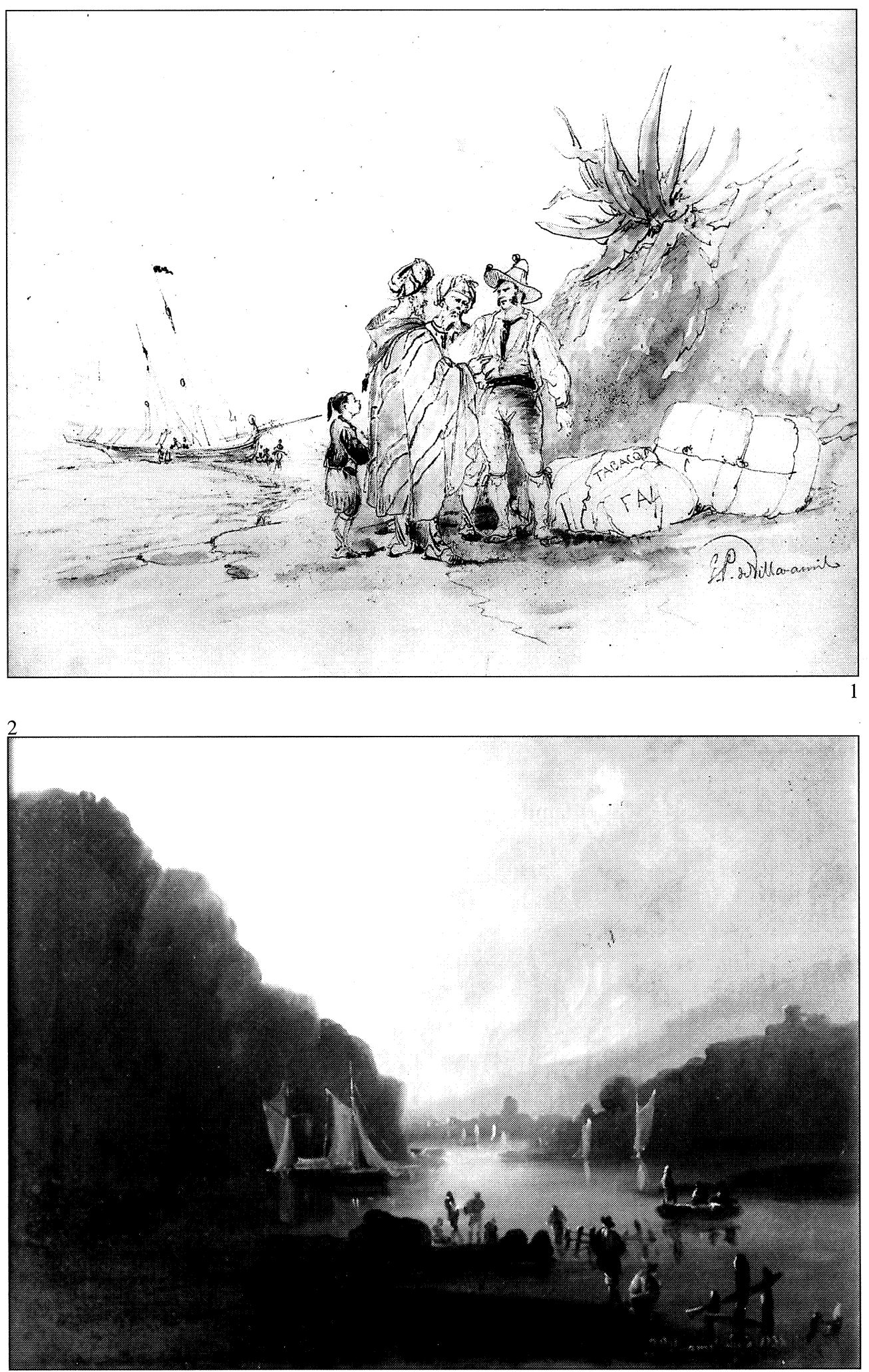

Fig. 1. Jenaro Pérez Villaamil: Contrabando de tabaco con el norte de África. Colección particular. Fig. 2. Juan Pérez Villaamil: Paisaje fluvial. Colección particular.

AEA, LXXVI, 2003, 304, pp. 407 a 436 
pero se aprecia claramente en la fotografía que su técnica es la del óleo, y por el tipo de craquelado, que se distingue con nitidez, su soporte ha de ser el lienzo. Nos representa un Paisaje fluvial (Fig. 2), visto todo al contraluz de un cielo de tonos rosados de atardecer, de luces muy románticas, que nos recuerda mucho a ciertos paisajes de su hermano Jenaro, y acercándose bastante a su calidad en este caso. Se trata de un cuadro que posee un buen estudio de la luz, muy representativo en sus calidades pictóricas de lo que era capaz de hacer Juan siguiendo las pautas paisajísticas románticas de su hermano Jenaro, al que aquí se asemeja mucho. Sin embargo, la inicial «J» del nombre en la firma es cosa definitiva para su adscripción a Juan y no a Jenaro, ya que en el siglo xix Genaro se escribía con «G» (y con tal inicial firmó siempre este pintor) y no con «J» como se hace actualmente.

Enlazando, de alguna manera, con los Pérez Villaamil, presentamos tres cuadros — que creo son los primeros que se dan a conocer- de un artista cuyas pocas obras aparecidas en el panorama artístico español, han sido erróneamente atribuidas a Jenaro Pérez Villaamil. Nos referimos al pintor británico, natural de Jamaica, Philipp Villamil, cuya similitud de apellido con el de nuestro artista, así como la semejanza de temática en algunas de sus obras, han hecho que por de Jenaro Pérez Villaamil se hayan tenido obras de este casi desconocido pintor británico ${ }^{3}$.

El asunto comenzó cuando, en 1958, dio a conocer Salas ${ }^{4}$ que había visto en Inglaterra una acuarela y cuatro escenas al óleo - pintadas estas últimas sobre un mismo cartón preparado—, todas ellas de asuntos taurinos, firmada la primera «P. Villaamil, Jamaica», mientras que las segundas «P. Villaamil of Jamaica». La acuarela estaba en la Galería Walker de Londres y formó parte de la exposición que ésta organizó en 1951 dedicada al toreo. Las cuatro escenas al óleo, las vio en 1956 en el comercio de Londres. Por obras de Jenaro Pérez Villaamil no solamente las tuvo Salas a todas ellas, sino que en el catálogo de la citada exposición dedicada a las corridas de toros de la Galería Walker, se interpreta la «P.» inicial de la firma de la acuarela exhibida como forma sincopada del apellido Pérez, con lo que dedujeron en la citada Galería que dicha firma debería de traducirse como «Pérez Villaamil of Jamaica» ${ }^{5}$, que es como figura en el mencionado catálogo. El extrañísimo apelativo geográfico de «Jamaica» tras el apellido Villamil en la firma de la acuarela, y más concretamente el de «of Jamaica» en la de las cuatro escenas al óleo —clarísima alusión, sin duda, al lugar de procedencia del artista que así firma-, fue interpretado por Salas como que en esa isla caribeña pasó nuestro Pérez Villaamil temporada larga, durante su viaje a Puerto Rico de 1830 a 1833 para decorar el teatro Tapia de San Juan, y que quizá se hiciese en Jamaica un nombre entre cierta clientela inglesa ${ }^{6}$; pero la realidad es que, de haber estado nuestro artista alguna vez en esa isla (cosa muy improbable), poco tiempo debió de permanecer en ella como para firmarse procedente de Jamaica.

Si estas obras le sirvieron a Salas para suponer una hipotética estancia de Jenaro Pérez Villaamil en Jamaica, en otro epígrafe del mismo artículo se ocupa en citar toda una serie de obras que, supuestamente, expuso nuestro pintor en la Royal Academy y en The British Institution entre 1838 y $1861^{7}$, por figurar en sus registros el nombre de Villamil. El hecho de que nuestro pintor falleciera en 1854, le lleva a pensar a Salas que o bien la familia siguió mandando obras suyas a Londres tras su muerte, o el que exponía, después de esa última fecha, era su hermano Juan que murió en $1863^{8}$. Pues bien, ni una cosa ni la otra, como a continuación veremos. Pues la realidad es que sólo algunas de las obras citadas por Salas, como obras de

\footnotetext{
${ }^{3}$ Arias Anglés, E., El paisajista romántico Jenaro Pérez Villaamil, Madrid, CSIC, 1986, p. 41.

${ }^{4}$ Salas, X. de, «Varias notas sobre Jenaro Pérez Villaamil», Archivo Español de Arte, núm. 124, 1958, pp. 285-286.

${ }^{5}$ Ibidem, p. 285, nota 19

${ }^{6}$ Ibidem, p. 286.

7 Ibidem, pp. 291 a 293.

${ }^{8}$ Ibidem, p. 293.
} 
Pérez Villaamil expuestas en Inglaterra, encajaría por su título — que es la única referencia que tenemos de ellas - dentro de la habitual temática de nuestro romántico gallego; y de éstas solamente podría considerarse como posible obra suya la titulada Catedral y muros de Burgos, expuesta en 1840 en la Royal Academy ${ }^{9}$, ya que la titulada Mujer de Frascati, también expuesta en 1838 en la misma Academy ${ }^{10}$, es asunto totalmente ajeno a la temática villaamilesca y no puede ser atribuida a nuestro artista, a pesar de que las señas que constan del pintor en esta ocasión son las de la casa Colnaghi, como representante suyo, y de que sabemos que en la única estancia segura que conocemos de Jenaro Pérez Villaamil en Inglaterra en 1841, siete cuadros que llevó allí estuvieron colgados en dicha casa con ánimo de venderlos ${ }^{11}$. El resto de las obras no pueden ser de Jenaro Pérez Villaamil ni tampoco de su hermano Juan, pues aparte de que las direcciones que se dan como de nuestro artista en los catálogos de la Royal Academy y la British Institution datan ya de 1854 (año de la muerte de nuestro romántico gallego) en adelante, y además son todas ellas direcciones de Londres ${ }^{12}$, hay títulos en inglés, como un largo versículo del Cantar de los Cantares u otro representando a la yegua favorita de la Reina Victoria de Inglaterra, que es imposible que sean de ninguno de los hermanos Pérez Villaamil ${ }^{13}$. Y, sin embargo, están registrados como de un pintor apellidado Villamil.

El problema quedó resuelto cuando Baticle, al publicar, en 1972, documentación de los Archivos Nacionales de París, dio la noticia de que un «Philipp Villamil» de nacionalidad inglesa proponía enviar una acuarela en 1855 a la Exposición Universal ${ }^{14}$. Con esto quedaba claro que las obras de asuntos taurinos vistas por Salas en Londres, y firmadas «P. Villamil of Jamaica», no eran de nuestro artista gallego sino de este Philipp Villamil, británico de Jamaica, claramente de origen hispano por su apellido; y de aquí quizá también su interés por los temas españoles, que, por cierto, tan bien se vendían en esos tiempos en Gran Bretaña. Igualmente, las obras rastreadas por Salas como supuestamente expuestas por nuestro Pérez Villaamil en la Royal Academy y The British Institution, por pura lógica pertenecerían a este artista británico de similar nombre que el nuestro, y con el que era fácil de confundir, pues al ignorarse su existencia, la coincidencia de la «P.» inicial de su nombre de pila Philipp con la inicial del apellido Pérez se prestaba fácilmente a ello. De hecho, no sólo por lógica, sino que la aparición de un cuadro de este pintor británico identificable con uno de los expuestos en la British Institution, citados por Salas, termina por confirmar lo supuesto, como a continuación veremos.

Tres son, como decimos, las obras aparecidas en España de este pintor británico, natural de Jamaica, llamado Philipp Villamil, del que no he encontrado más noticias por el momento. Ninguna de ellas está fechada, pero las tres están firmadas «P Villamil», siendo las firmas y sus grafías idénticas, teniendo además el característico rasgo de enlazar la parte superior de la «P» con la superior de $\mathrm{la}$ «V» mediante un inconfundible lazo gráfico (Fig. 3); una de ellas posee además bajo la firma el añadido del topónimo de «Jamaica». Idéntica, igualmente, es la técnica de los tres cuadros, bastante lisa, lamida incluso en algunos trozos.

La primera de ellas, por el orden cronológico que me han ido llegando, es la que podríamos titular La carta de amor (Fig. 4); escena costumbrista andaluza en la que dos jóvenes se pasan furtivamente un escrito, en el pórtico de una iglesia, aprovechando el descuido de la vieja beata, que sirve de «carabina» a la chica, mientras toma agua bendita de la pila. El asunto y la forma de tratarlo no pueden ser más ajenos a la pintura de nuestro Jenaro Pérez Villaamil. No vamos a en'trar en más disquisiciones o comparaciones, porque no merece la pena. Basta con verlo. Esto es

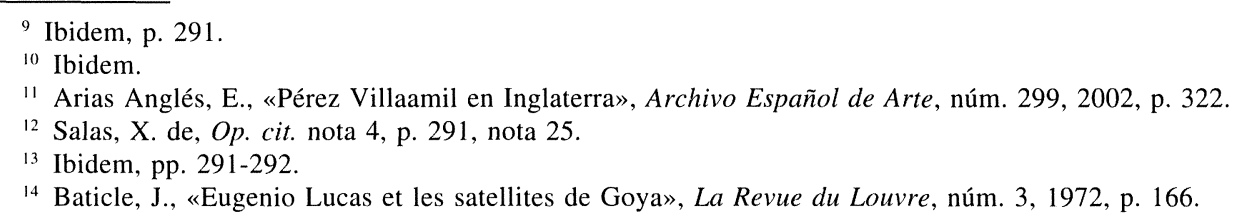

AEA, LXXVI, 2003, 304, pp. 407 a 436 


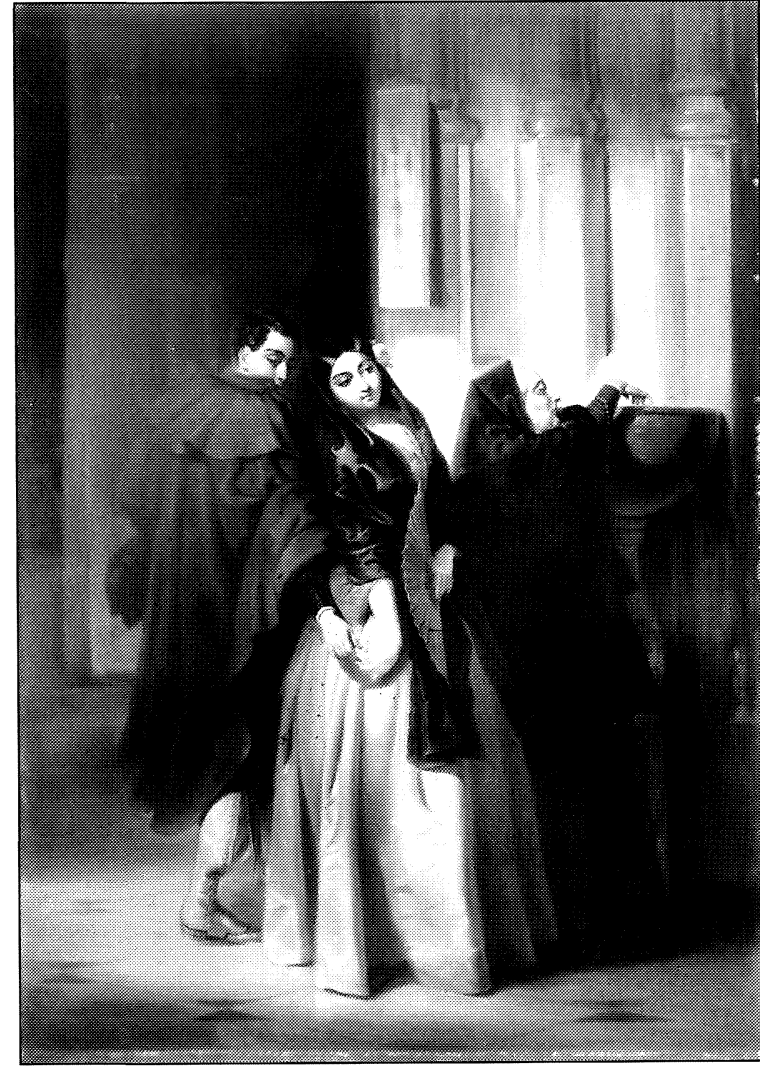

Fig. 4. Philipp Villamil: La carta de amor. Colección particular.

obra, sin duda, de otro pintor. Es óleo sobre lienzo, pero desconozco sus dimensiones. Apareció hace algún tiempo en el comercio de Madrid y debe de encontrarse hoy en colección privada. Se halla firmada hacia el ángulo inferior derecho, bajo las sayas de la vieja, «P Villaamil / Jamaica». Este es, sin duda, el pintor que cita Salas y que confundió, en su día, con nuestro Jenaro Pérez Villaamil, por las escenàs taurinas por él vistas en Londres y firmadas «P. Villaamil. Jamaica» $\mathrm{y}$ «P. Villaamil of Jamaica» respectivamente; como del que así mismo son las obras expuestas en la Royal Academy y The British Institution que también cita Salas atribuyéndolas a nuestro Pérez Villaamil. De hecho, la temática de este cuadro que tratamos, se nos antoja no muy lejana a ese otro cuadro que Salas cita como expuesto en la Royal Academy en 1859, con el núm. 235, y cuyo título era Lenguaje de los ojos ${ }^{15}$, y que muy probablemente se refiera también a una escena de asunto similar, igualmente andaluz.

La segunda de estas obras es otro óleo sobre lienzo, del que también desconozco sus dimensiones, y se encontraba hará dos años en colección particular gallega. Por su asunto lo podríamos titular Marineros y vendedoras de pescado en un muelle (Fig. 5), y que por las barretinas que llevan los varones podría tratarse de alguna escena costumbrista catalana; aunque la barretina es un gorro no sólo de Cataluña, sino también de otras regiones mediterráneas, pudiendo también tratarse de una escena del mediodía de Francia o incluso de Italia. Sea como fuere, la técnica, el estilo y la temática, nada tienen que ver con la pintura de nuestro Pérez Villaamil, por mucho que la firma, situada en el ángulo inferior derecho, encima de las redes, rece «P Villamil». Sin embargo, la firma, su grafía, es idéntica a la del cuadro anterior, excluyendo el topónimo «Jamaica», que esta no posee. La forma de tratar los tejidos y sus pliegues, así como la configuración y construcción de los rostros femeninos y masculinos son todos ellos también exactos a los del cuadro anterior.

Como igualmente lo son también a los del tercer cuadro que traemos de este desconocido artista británico. Se trata asimismo de un óleo sobre lienzo, de 1,13 × 1,47 m. (Fig. 6), de colección particular, cuyo asunto encaja además plenamente con el título de uno de los cuadros erróneamente citados por Salas como expuesto por Pérez Villaamil en la British Institution; concretamente con el titulado El corral de la plaza de Sevilla antes de la corrida, exhibido en la citada Institution en 1854 (año de la muerte de Jenaro Pérez Villaamil), con el núm. 537 y valorado en el catálogo en 200 libras ${ }^{16}$. Creo, realmente, que nos encontramos ante el mismo cuadro; pues el asunto del que estamos tratando es exactamente el del corral de la plaza de toros de

\footnotetext{
15 Salas, X. de, Op. cit., nota 4, p. 291.

16 Ibidem.
} 


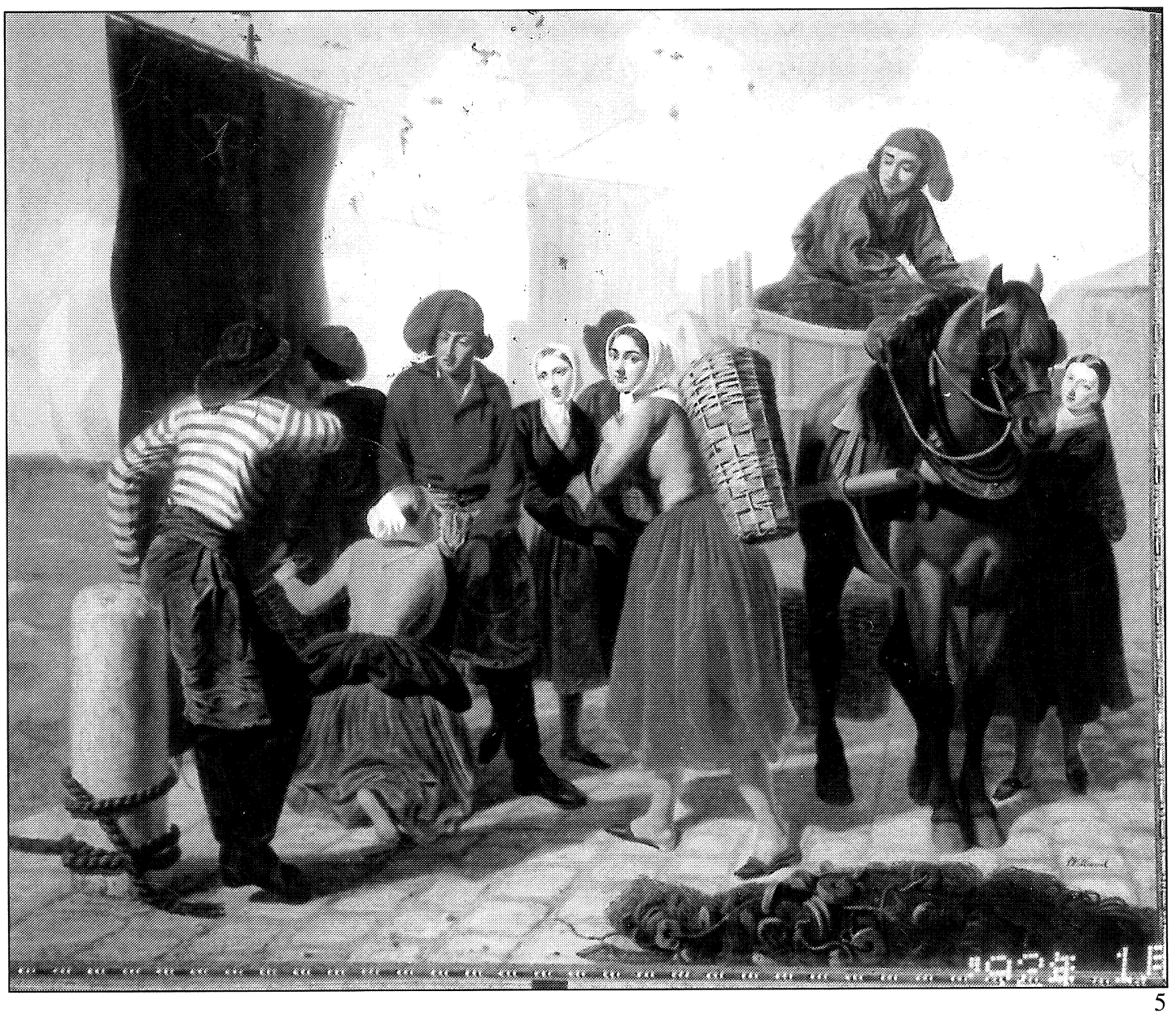

3

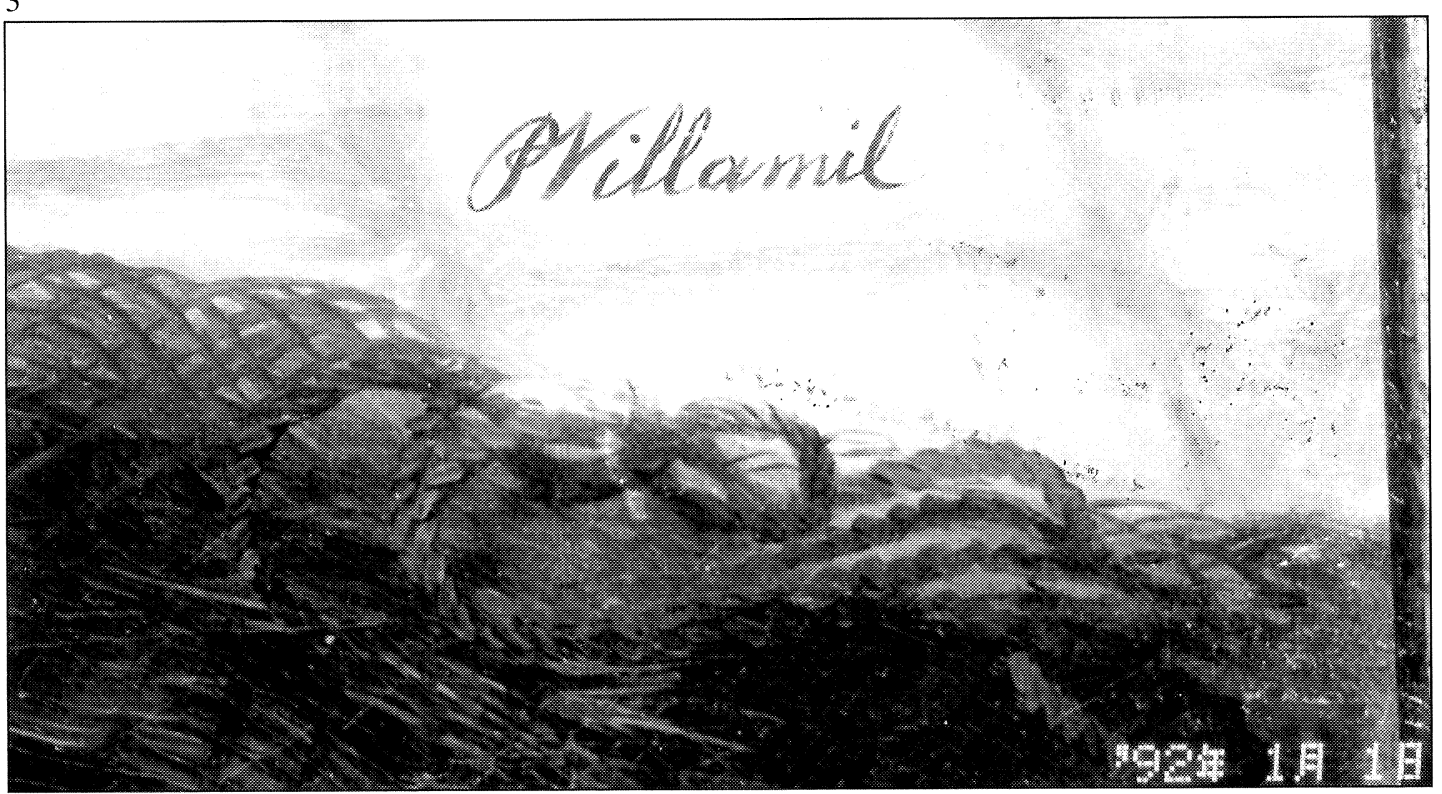

Fig. 5. Philipp Villamil: Marineros y vendedoras de pescado en un muelle. Colección particular.

Fig. 3. Firma de Philipp Villamil en el cuadro Marineros y vendedoras de pescado en un muelle. Colección particular

AEA, LXXVI, 2003, 304, pp. 407 a 436 
Sevilla antes de la corrida, como nos confirma el cartel de toros que se halla pegado a la blanca pared en el lateral izquierdo del cuadro, donde puede leerse claramente «Plaza de Sevilla / Corrida de toros». Así pues, pensamos que no hay duda de que esta obra es la que fue expuesta en 1854 en The British Institution. Y, si no, en el peor de los casos, nos hallamos ante una réplica realizada por el mismo artista. La obra está firmada también en el ángulo inferior derecho del cuadro «P Villamil Sevilla», con lo que el pintor nos está diciendo claramente que viajó por España en torno a 1850. Como nos corrobora además el hecho de que el cuadro que ese mismo año de 1854 expuso en la Royal Academy llevara por título Un grupo de la Feria de Sevilla; y que en 1855 expone en la Institution Una escena en una venta de Andalucía; en 1857 cuelga en la Royal Academy The roofs of Seville (Los tejados de Sevilla); en 1860, en la Institution, el cuadro titulado en español Los nazarenos, dando cumplida cuenta el catálogo de lo que son esas cofradías de Semana Santa españolas; en 1861 uno titulado La jaca andaluza en la Royal Academy; y en 1861, último año en que aparece su nombre entre los expositores, exhibe en la Institution el cuadro titulado La azotea, de clara alusión también a un asunto andaluz ${ }^{17}$. Entre medio de estos cuadros de asuntos andaluces, expuso también, en ambas instituciones, otros de claro matiz británico.

En estos dos últimos cuadros, el mayor número de figuras existentes que en el primero, nos lleva, además de los inconfundibles rasgos de la firma, a una mejor comparación técnicoestilística. Así, junto a su lisa técnica y a la muy semejante configuración de los rostros en uno y otro cuadro, hemos de añadir una mayor precisión en cuanto a la apreciación en la manera de realizar los tejidos. Así, por ejemplo, la textura y pliegues de la falda de la figura central femenina, que porta un canasto de mimbre a su espalda, en el cuadro de asunto marinero, coinciden plenamente con los de la capa que lleva el personaje de espaldas en el centro derecha del cuadro del corral de la plaza de Sevilla; como así mismo los pliegues y arrugas de la falda de la mujer que se halla de rodillas, en el lateral del cuadro de asunto marinero, coinciden exactamente con los de la falda de la mujer que está de espaldas en el lateral izquierdo del cuadro del corral de la plaza de Sevilla; igualmente, las arrugas del pantalón del marinero que está apoyado en un noray del puerto, de espaldas al espectador, son plenamente coincidentes con las del torero que, en el extremo del lateral izquierdo del otro cuadro, mira por encima del hombro del personaje con el que charla.

Estos tres cuadros, que llegaron a mi mano increíblemente atribuidos a Jenaro Pérez Villaamil, nos muestran las primeras obras que se conocen en España de este ignorado pintor británico, llamado Philipp Villamil. Esperamos que con esto se deshaga definitivamente el equívoco.

Pasando del Romanticismo al Realismo, vamos a ocuparnos ahora de un cuadro del gran maestro del paisajismo realista español Carlos de Haes, y que titularemos Paisaje montañoso (Fig. 7). Se trata de un óleo sobre lienzo, de $0,515 \times 0,73 \mathrm{~ms}$., firmado con tono amarronado en el ángulo inferior izquierdo «C. de Haes», y que es muy semejante en estructura compositiva y asunto a otro que publicamos en esta misma revista en el año $2002{ }^{18}$, perteneciendo ambos a la colección Rudolf Gerstenmaier (Madrid).

Tanto éste como el anterior cuadro que publicamos son dos magníficos paisajes de los denominados de alta montaña y poseen los dos una estructura compositiva general muy similar, con ligeras variantes en el cuadro que analizamos ahora: un arroyuelo, de aguas limpias y turbulentas, fluye por el centro de la composición, viniendo del fondo, en medio de un abrupto valle; paralelamente a él discurre un camino por el que transitan dos diminutas figuras femeninas al parecer. A izquierda y derecha del arroyo, en las laderas ascendentes del valle, destacan, entre su vegetación, macizos de pinos de alta montaña, someramente apuntados a base de pe-

\footnotetext{
${ }^{17}$ Ibidem, pp. 291-292.

18 Arias Anglés, E., «Sobre tres paisajes de alta montaña de Haes», Archivo Español de Arte, núm. 297, 2002, p. 60, Fig. 3.
} 

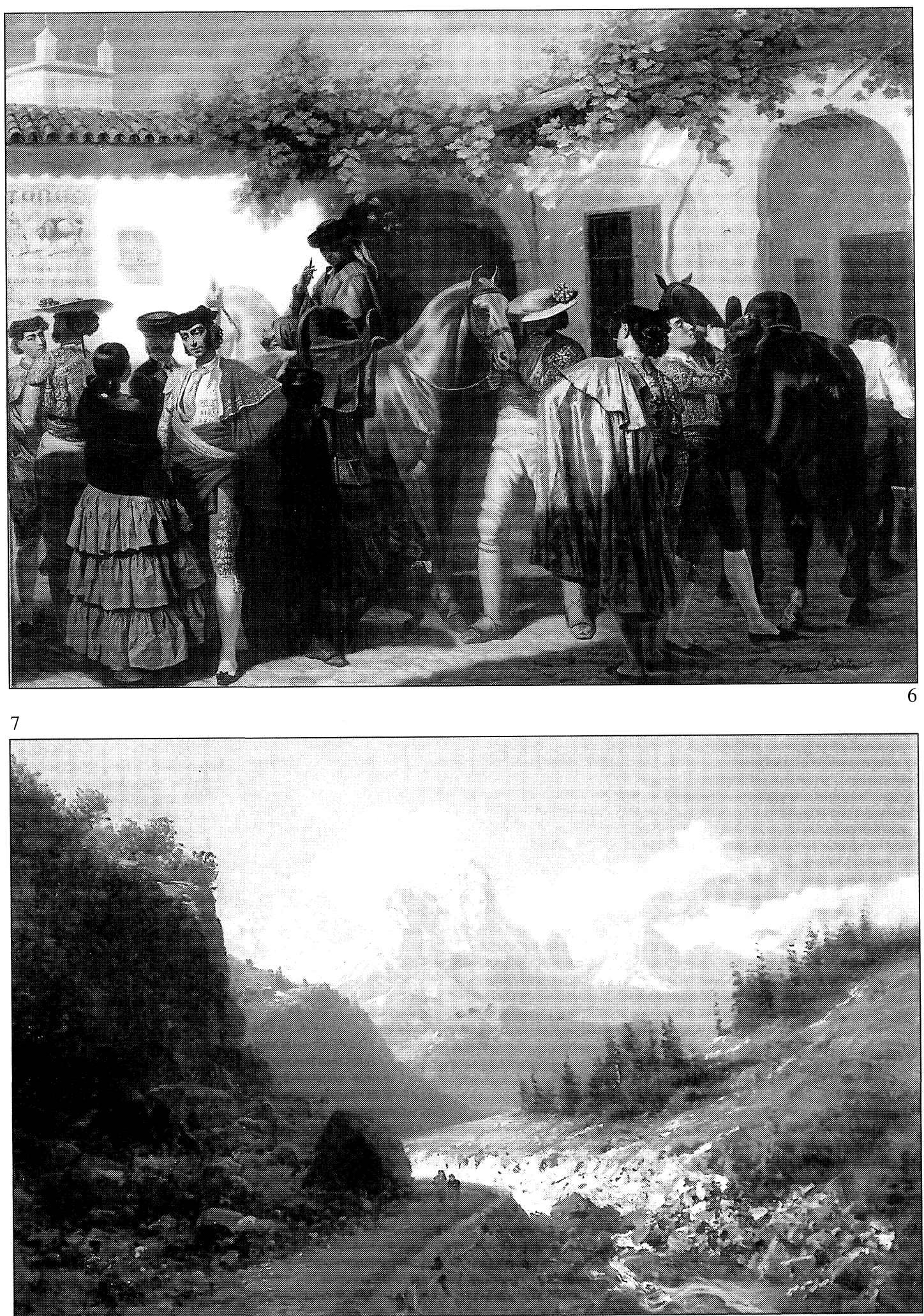

Fig. 6. Philipp Villamil: El corral de la plaza de Sevilla antes de la corrida. Colección particular. Fig. 7. Carlos Haes: Paisaje montañoso. Colección Rudolf Gerstenmaier. Madrid.

AEA, LXXVI, 2003, 304, pp. 407 a 436 
queños toques de manchas de color; éstos, junto con algunas estribaciones montañosas en penumbra, conforman, en los términos medios de la composición, la pantalla referencial que marca la lejanía y profundidad de los grandes picos montañosos que se elevan al fondo del cuadro, inundados de luz, y coronados por el límpido azul de un cielo por el que discurren blanquísimas y huidizas nubes. Se trata pues, de dos paisajes de gran belleza y maestría; si bien este segundo que analizamos ahora es de mayor luminosidad, frescura y espontaneidad.

Al igual que ocurría con el anterior cuadro que publicamos, el hecho de tratarse de un paisaje de alta montaña nos permite situar con bastante precisión su etapa de realización dentro de la producción general de Haes, ya que éste empezó a interesarse por dichos temas montañosos en $1872{ }^{19}$, cuando fue a pintar en verano a Santander y Vizcaya, descubriendo así los paisajes del norte de España, tan semejantes en climatología y atmósfera con los del centro y norte de Europa, a los que él estaba tan habituado. Luego, en 1874, viaja a Asturias, descubriendo las bellezas de los Picos de Europa, que plasma repetidamente, pasando en ese mismo año a Vascongadas y Navarra, viaje que volvió a hacer en $1875^{20}$. Por tanto, el período que discurre entre 1872 y 1875 , es en el que se inscribe básicamente el interés de Haes por los paisajes de alta montaña.

Es pues dentro de esta etapa en la que podemos fechar el cuadro que nos ocupa. Y todavía, más concretamente entre 1874 y 1875, años en los que descubre los Picos de Europa y los Pirineos; pues se trata, sin duda, de una vista de alguna de estas dos cordilleras. La dificultad estriba en precisar de cual de las dos se trata, ya que de no ser un perfecto conocedor de las mismas sobre el terreno, resulta verdaderamente difícil su identificación. Nosotros, al analizar el anterior cuadro de la colección Gerstenmaier, nos inclinamos por identificar el paisaje, con ciertas reservas, como de los picos de Europa. Este nuevo que tratamos, equivalente en estructura compositiva, con idéntica vegetación de coníferas y gran semejanza de las montañas del fondo, nos tienta a pensar que de las mismas montañas se trate y que sea un paisaje de los Picos de Europa, pero siempre con las mismas reservas que en el anterior cuadro.

En cuanto a su estilo, al igual que ocurría con el otro óleo, encaja por su técnica y colorido plenamente dentro de la etapa de su producción que discurre entre 1870 y 1880 , la segunda de las tres que estableció Cid Priego para la clasificación de su obra ${ }^{21}$. En este período, Haes abandona tanto la fuerte construcción dibujística, como los tonos terrosos y los asfaltos que dominaron en la obra de su primera etapa; siendo sustituido todo ello por una pintura de factura más suelta, un más alegre y brillante colorido y un aclaramiento general de su paleta.

Es decir, que dentro del más amplio período de realización de la obra que nos proporciona el análisis de su técnica, podemos precisar aún con mucha más concreción su fecha de ejecución por medio de la temática; ya que, como decimos, estos paisajes de alta montaña, específicamente de la cordillera cantábrica y de los Pirineos, los descubrió Haes en las campañas pictóricas de entre 1872 y 1875 . Aunque Haes no debió de limitar su producción de paisajes de alta montaña a este período y, sin duda, realizaría posteriormente algunos en su taller sobre bosquejos tomados del natural en esos años que apuntamos, la suelta factura de carácter manchista y la frescura de tratamiento de este que estudiamos, su espontánea luminosidad, así como su tamaño, nos hace pensar que fuese realizado del natural y no ser obra posterior de taller. De aquí que su fecha de ejecución se ajuste muy probablemente a los años que hemos indicado antes.

Y, por último, traemos dos cuadros, dos magníficos bodegones - que se encuentran en colección particular española-, de un pintor francés de la segunda mitad del siglo XIX y primera

\footnotetext{
${ }^{19}$ Pena, M.C., El paisaje español del XIx: del naturalismo al impresionismo, Universidad Complutense, Madrid, 1982, p. 195.

${ }^{20}$ Ibidem, p. 198.

${ }^{21}$ Cid Priego, C., Aportaciones para una monografía del pintor Carlos de Haes, Instituto de Estudios Ilerdenses (CSIC), Lérida, 1956, pp. 18, 21 y 22.
} 
del $\mathrm{xx}$, del que creemos que son las primeras obras de que tenemos noticia que se encuentren en España y, además, se den a conocer en nuestro país. Nos referimos a Hubert-Denis Etchéverry, retratista y pintor de género, nacido en Bayona (Basses-Pyrénées) el 21 de septiembre de 1867 y muerto en la misma ciudad el 3 de abril de 1950. Etcheverry hizo sus primeros estudios en una escuela local de Bayona, y luego pasó, en 1888, con una ayuda estatal, a estudiar a la Escuela de Bellas Artes de París, siendo discípulo de Bonnat, de Zo, y de Albert Maignan. En 1892 obtuvo el segundo gran premio de Roma por su cuadro Philémon y Baucis (Museo de Bayona). En el Salón de1895 consiguió una medalla de tercera clase y, posteriormente, en el de 1899 una segunda medalla, y en 1900 una de plata en la Exposición Universal. Fue, además, profesor de dibujo de la Escuela Especial de Arquitectura. Habiendo iniciado su andadura profesional en la pintura de historia, pronto se inclinó por la pintura de género y el retrato, especializándose en los cuadros de asunto mundano y de género erótico. Fue uno de los buenos pintores de su época, siendo hábil dibujante y avezado colorista, utilizando generalmente en sus cuadros un colorido cálido y pintoresco ${ }^{22}$.

Curiosamente este pintor no firmó sus obras con el primero de sus dos nombres, Hubert, sino con la inicial del segundo, Denis. De aquí que en el conocido diccionario de artistas Thieme-Becker se le cite como «Etchéverry, Denis», añadiendo detrás, entre paréntesis, su nombre completo de Hubert Denis ${ }^{23}$; pero, además, para despejar cualquier duda al respecto, en el también afamado diccionario de Benezit se reproduce su habitual firma claramente como «D. Etcheverry» ${ }^{24}$, forma en la que están firmados también los cuadros que traemos.

Se trata de dos óleos sobre lienzo, de 0,60 $\times 0,73$ ms., firmados ambos en el ángulo superior izquierdo «D. ETCHEVERRY / 1887», y que titularíamos Bodegón con gallinas (Fig. 8) y Bodegón con caldero (Fig. 9). Sus idénticas dimensiones, mismo lugar de las firmas (poco habitual, por cierto), e igual año de ejecución, así como su también coincidencia en la temática del bodegón, claramente nos indican que son pareja, que fueron concebidos por el pintor para formarla, probablemente debido a un encargo expreso que se le hiciese al respecto para decorar el comedor de algún particular. Y decimos esto, porque, como hemos visto más arriba, no fue una temática habitual en nuestro pintor la del bodegón; teniendo, por lógica, que deberse más a un encargo que a un interés especial del artista por estos asuntos. Y si nos fijamos, además, en su fecha de ejecución (1887), nos damos cuenta de que Etcheverry tenía veinte años al momento de pintar estos cuadros y de que los realizó, firmó y fechó justo el año anterior de su partida a París para continuar sus estudios en la Escuela de Bellas Artes, que, según antes vimos, fue en el año 1888. Por tanto, los cuadros fueron pintados en Bayona por el joven Etcheverry y muy probablemente por encargo de algún cliente, siendo testimonios de que, ya antes de su partida a París, intentaba ganarse la vida con la pintura. De aquí que su interés sea doble; por un lado por tratar ambos un tipo de asunto en el que si posteriormente incidió en él fue, al parecer, escasamente, por las noticias que tenemos de su tipo de producción; y por el otro, por tratarse de dos obras situadas claramente en la bisagra que representa el último año de su formación en Bayona, justo antes de marchar a la Escuela de Bellas Artes de París.

Son, como decimos, dos hermosos bodegones. Uno de ellos (en el que peor se ve la firma) (Fig. 8) nos muestra al primer término un plato lleno de granos de maíz, estando algunos desparramados por el suelo, frente al que se hallan tumbadas dos gallinas con las patas atadas; tras ellas, una cesta llena de hortalizas, y rodeada de verduras. El otro (en el que la firma es más

\footnotetext{
${ }^{22}$ Los datos biográficos de este pintor han sido sacados de: Thieme-Becker, Allgemeines Lexikon Der Bildenden Künstler, t. XI, Leipzig, 1915, p. 58; Enciclopedia Universal Ilustrada Europeo-Americana, Espasa-Calpe, S.A., t.XXII, Madrid, 1975, p. 1174; Benezit, E., Dictionnaire critique et documentaire des peintres, sculpteurs, dessinateurs et graveurs, París, 1976, p. 207

${ }^{23}$ Thieme-Becker, Op. cit., nota 22, p. 58 .

${ }^{24}$ Benezit, E., Op. cit. nota 22, p. 207.
}

AEA, LXXVI, 2003, 304, pp. 407 a 436 


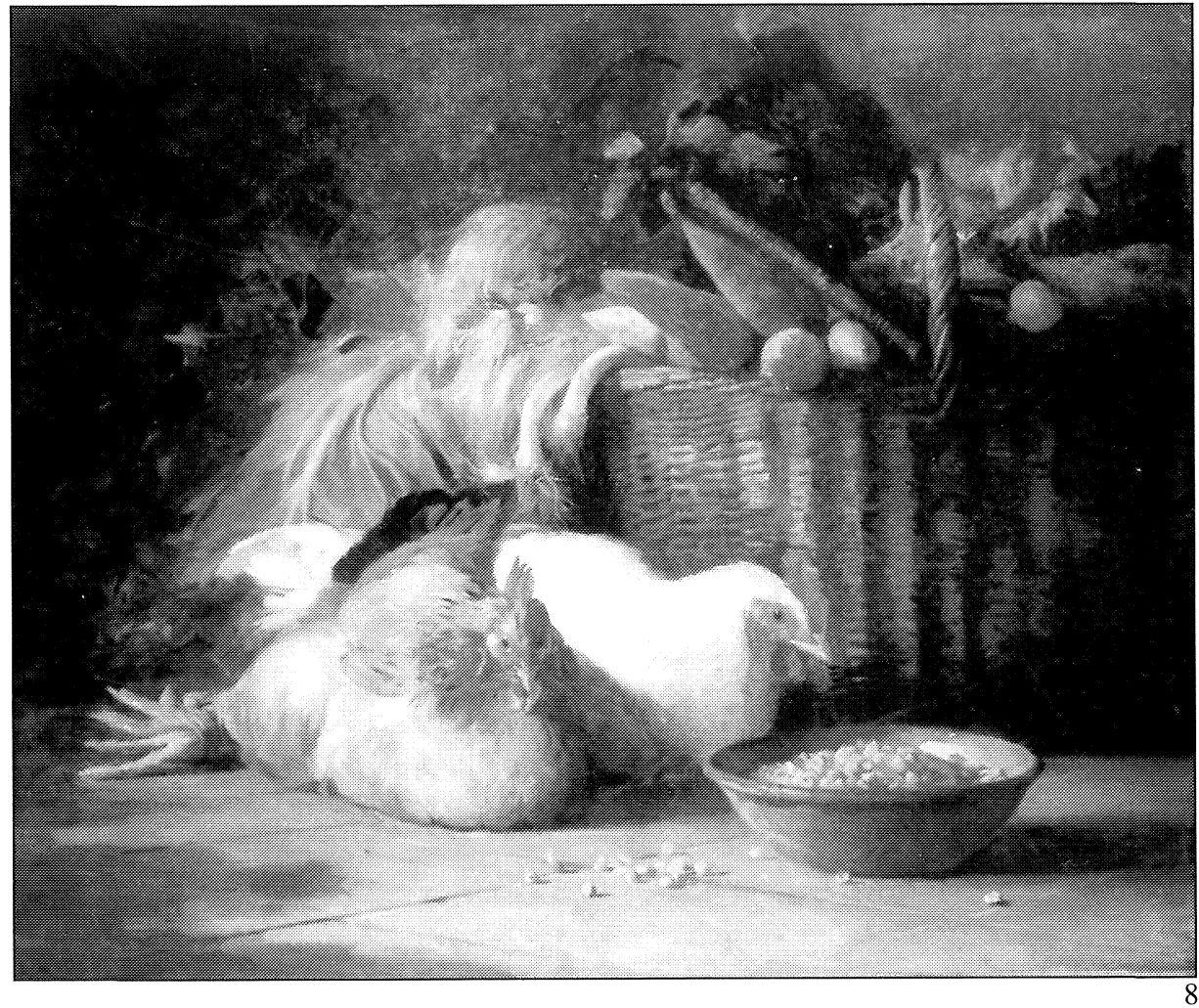

9

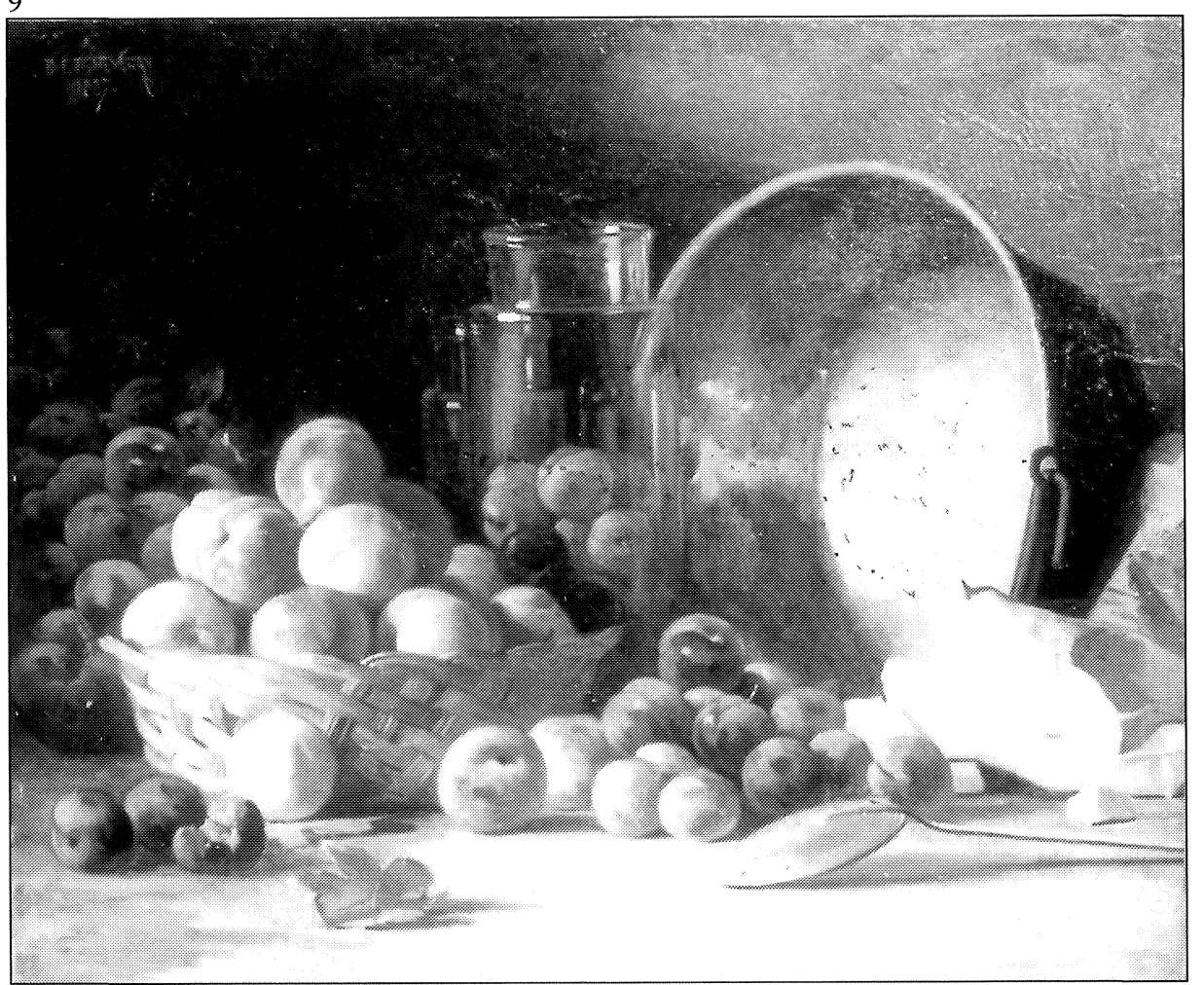

Fig. 8. Hubert Denis Etchéverry: Bodegón con gallinas. Colección particular. Fig. 9. Hubert Denis Etchéverry: Bodegón con caldero. Colección particular.

AEA, LXXVI, 2003, 304, pp. 407 a 436 
clara) (Fig. 9) nos representa, en ligera diagonal, un cesto de melocotones, rodeado de ciruelas amontonadas, tras el que se ve un bote de cristal medio lleno de dichas frutas y tras el que también está un caldero de cobre, teniendo a su lado trozos al parecer de azúcar, junto a unas bolsas comerciales de papel, y una espumadera más hacia el primer término. Ambos bodegones poseen una magnífica calidad en la representación de los diversos tipos de materia que nos muestran. Sus composiciones son serenas, sin ningún tipo de barroquismos. Todo dentro de un realismo excepcional y sin estridencias, acompañado de una luz que apoya suavemente la ligera diagonal presente en las composiciones. En resumen, dos curiosas e interesantes composiciones en la producción de este artista, que nos muestran las magníficas cualidades y calidades pictóricas de un Etcheverry antes de su partida para París.

ENRIQUe ARIAS ANGLÉS

\section{DON PEDRO DE ARCE ¿COLECCIONISTA O REGATÓN?, Y LAS HILANDERAS DE VELÁZQUEZ}

Dícese regatón del que compra al por mayor para vender más caro al detalle, afirmó don Sebastián de Covarrubias en su Tesoro de la lengua castellana o española (Madrid, 1611) ${ }^{1}$.

A nuestra historiografía artística le cuesta mucho esfuerzo la revisión de algunas de las asunciones adquiridas en el pasado, sea éste remoto o relativamente reciente. Una de las causas de nuestra pereza puede ser la autosatisfacción colectiva ante lo que consideramos, en algún momento de ese pasado pero también del presente, un logro, sea artístico, cultural o político. Una de ellas es, en nuestra opinión, la culta audiencia — que en absoluto se ha de excluir- de Las hilanderas de Diego Velázquez, representada, sin embargo, por un supuesto culto y experto coleccionista de pintura, don Pedro de Arce, en cuyo poder aparecía como «La fábula de Aragne» por vez primera, en 1664, cuatro años después de la muerte del pintor sevillano. Don Pedro de Arce y Portillo no se nos muestra hoy, sin embargo, tras una revisión de los documentos utilizados hasta la fecha y tras la consideración de algunos nuevos, como un típico y cultivado coleccionista de pintura, sino más bien como un inversor en diferentes bienes de lujo, entre los que se contaban los lienzos, pero que no parece haber poseído ni un solo libro; incluso fue acusado -y no dejaba de ser importante en la sociedad estamental de la época- de haber trabajado, previamente a sus cargos de montero de Espinosa y ensayador de las Casas de la Moneda de Toledo y Madrid, nada menos que como platero con tienda, y como tratante en joyas. A estos malentendidos, pretéritos y actuales, dedicaremos estas páginas.

El protagonista de esta historia es el montero de Espinosa y residente en Madrid don Pedro de Arce y Portillo (Madrid, 1 de marzo de 1607-1671); hijo del platero Juan de Arce, de Espinosa de los Monteros, y de doña Juana Bautista Portillo, de Alcalá de Henares, nuestro hombre había casado, en primeras nupcias, en 1642 con doña María Tofiño Vallejo (16091656), viuda hasta entonces del mercader de joyería, y familiar del Santo Oficio de la Suprema Inquisición, don Tomás de Rueda $(† 1640)$. Una serie de precisos inventarios de bienes de los dos nuevos cónyuges se realizó para aclarar primero la curaduría de sus hijastros Tomás ${ }^{2}$ y Jacinto de Rueda ${ }^{3}$, después para controlar esa curaduría e inventariar en 1657 los bienes de la

\footnotetext{
' Este artículo se presenta como desarrollo de uno de los puntos tocados en mi ensayo «Tiziano y Velázquez, tópicos literarios y milagros del arte», en Tiziano, ed. Miguel Falomir Faus, Museo del Prado, Madrid, 2003, pp. 111-132 (trad. inglesa, «Titian and Velázquez, Literary Topoi and Miracles of Art», en Tiziano, 2003, pp. 339-346).

${ }^{2}$ Archivo Histórico de Protocolos de Madrid (A.H.P.M.), e. p. Nicolás Martínez Serrano, Pr. 8.228, fol. 135.

${ }^{3}$ A.H.P.M., Pr. 8.228, fol. 275.
}

AEA, LXXVI, 2003, 304, pp. 407 a 436 